\title{
SOBRE O COMPROMISSO POLÍTICO DA EDUCAÇÃO ESCOLAR E AS PRÁTICAS DE AVALIAÇÃO DO ENSINO-APRENJIZADO
}

\author{
ON THE POLITICAL COMMITMENT TO SCHOOL EDUCATION AND PRACTICES \\ FOR ASSESSING TEACHING-LEARNING
}

\author{
Leonardo Nunes Domingos ${ }^{1}$ e Danielle Piontkovsky ${ }^{2}$
}

1Instituto Federal do Espírito Santo, Brasil, E-mail: leodnl@gmail.com, ORCID: https://orcid.org/00000002-8942-930X

Instituto Federal do Espírito Santo, Brasil, E-mail: danielle.ifes@gmail.com, ORCID: https://orcid.org/0000-0003-0824-5275

ARTICLE IN F O

Article history:

Received 2020-09-28

Accepted 2020-12-12

Available online $2020-12-12$
Palavras-chave: Avaliação do ensino-aprendizado. Compromisso político. Regulação.

Keywords: Assessing teaching-learning. Political commitment. Regulation.

RESUMO. A escola moderna, constituída no contexto histórico capitalista como instrumento de reprodução do sistema, seja pela socialização dos novos membros aos códigos sociais, seja pela manutenção ou agravamento das desigualdades sociais existentes, também abre, contraditoriamente, a possibilidade de transformação dessa realidade. Isso ocorre, quando a educação formal, ancorada ao compromisso político de ampliar o acesso aos conhecimentos produzidos pela humanidade, promove a potencialização da atuação do homem na construção coletiva de uma sociedade mais justa e igualitária. Nesse contexto, e considerando a avaliação do ensino-aprendizado como ferramenta crucial para a consecução do compromisso político assumido pela educação, buscaremos investigar os processos de regulação capitalista na educação a partir do estudo das teorizações de avaliação. Para isso, optamos pela abordagem qualitativa, de cunho exploratório e com o uso de pesquisa bibliográfica, com base em Minayo (2009) e Gil (2002). Nessa análise, conforme a organização de Fernandes (2009), privilegiamos as teorizações partidárias da terceira e da quarta gerações de avaliação, cujos autores - notadamente Afonso (2000), Esteban (2001; 2008; 2010), Luckesi (2011), Lugli e Gualtieri (2012) e Vasconcellos (2000) - reconhecem o seu carácter sociológico, em detrimento de uma visão estritamente operacional da avaliação. Identificamos que os processos de regulação escolar, realizados por meio da avaliação do ensino-aprendizado, podem ocorrer de forma imediata e/ou mediata, levantando a necessidade de colocar em suspeição as práticas avaliativas cristalizadas ao longo do tempo.

ABSTRACT. The modern school, which arised in the historical capitalist context as an instrument for the
reproduction of the system, either through the socialization of new members to social codes, or through the
maintenance or aggravation of existing social inequalities, contradictorily also opens the possibility of
transforming this reality. This occurs when formal education, anchored to the political commitment to expand
access to the knowledge acquired by humanity, promotes the potentialization of man's action in the collective
construction of a more fair and egalitarian society. In this context, and considering the evaluation of teaching-
learning as a crucial tool for the achievement of the political commitment assumed by education, we will seek
to investigate the processes of capitalist regulation in education from the study of evaluation theorizations. For
that, we opted for a qualitative approach, of exploratory nature and using the bibliographic research, based on
Minayo (2009) and Gil (2002). In this analysis, according to the organization of Fernandes (2009), we focused
the party theorizations of the third and fourth generation of evaluation, authors who - notably Afonso (2000),
Esteban (2001; 2008; 2010), Luckesi (2011), Lugli and Gualtieri (2012) and Vasconcellos (2000) - recognize
its sociological character, to the detriment of a strictly operational view of evaluation. We identified that the
schooling regulation processes, carried out through the evaluation of teaching-learning, can happen
immediately and / or mediately, raising the need to place suspicion about how the evaluative practices
crystallized over time. 


\section{Introdução}

Diferentemente dos outros animais, a espécie humana não se limita a adaptar-se à natureza. De forma planejada e deliberada, o homem, por meio do trabalho, a transforma em prol do atendimento de suas necessidades materiais (MARX e ENGELS, 1998). Nessa perspectiva, trabalho é considerado "[...] o ato de agir sobre a natureza transformando-a em função das necessidades humanas [...]", conforme explica Saviani (2007, p. 154).

As necessidades humanas, entretanto, não se limitam às necessidades materiais. Ao realizar trabalho, o homem produz sua realidade material e também sua realidade não material, representada pela ciência, arte, cultura, tecnologia, costumes, etc. Para Leontiev (1978, p. 263), "Os progressos realizados na produção de bens materiais são acompanhados pelo desenvolvimento da cultura dos homens; o seu conhecimento do mundo circundante e deles mesmos enriquece-se, desenvolvem-se a ciência e a arte".

O trabalho é, portanto, uma condição fundante do homem, porque tudo o que distingue esse ser dos demais animais - cultura, religião, produção de ciência, etc. - se dá por meio da sua realização. Podemos afirmar, com base em Marx e Engels (1998, p. 14), que "O homem se diferencia dos outros animais por muitas características, mas a primeira, determinante, é a capacidade de trabalho[...]", e, com base nisso, que "[...] a essência humana é produzida pelos próprios homens" (SAVIANI, 2007, p. 154).

Em virtude dessa condição humana, apesar de ser biologicamente um animal, o homem não tem mais na sua genética o fator determinante de sua amplitude de interação com o meio ambiente que o circunda. Ao organizar-se em sociedade, desenvolver linguagem, engendrar ferramentas para intermediar sua atuação com a natureza, desde as mais rudimentares até as mais modernas, o ser humano se liberta das determinações biológicas e passa a ser influenciado fundamentalmente pelas "leis sócio-históricas" constituídas pelas gerações anteriores (LEONTIEV, 1978).

Essa perspectiva é crucial para compreendermos o papel da formação humana mais ampla. A socialização de conhecimentos entre as gerações humanas permite, primeiro, que as novas gerações se apropriem dos conhecimentos, dos costumes e dos signos sociais de uma determinada sociedade e, segundo, que avancemos - por vezes, de forma não linear, mas pela contradição - no desenvolvimento cultural, artístico, científico e tecnológico com base naquilo que já foi constituído. Permite, em outras palavras, que a humanidade se perpetue (LEONTIEV, 1978).

No contexto histórico do capitalismo, nascido na Revolução Burguesa dos séculos XVII e XVIII, e, como resultado da indústria moderna (que exacerba a divisão do trabalho), o trabalho tem assumido cada vez mais seu sentido histórico (determinado pelas relações 
sociais e políticas do capitalismo, por meio da venda da força de trabalho) à medida que se afasta do ontológico (como forma constitutiva do homem), deixando, com isso, cada vez mais, de ser uma expressão humana para se tornar uma "força estranha" a ele. Em outras palavras, o trabalho se torna, cada vez mais, sinônimo de emprego. Como afirmado por Marx e Engels (1998, p. 82): “[...] hoje, manifestação de si e produção da vida material são de tal modo separadas que a vida material aparece como a finalidade, e a produção da vida material, isto é, o trabalho, como sendo meio [...]".

Nesse sentido, a classe que domina os meios de produção passou a utilizar o conhecimento científico para o domínio da natureza e a otimização das capacidades produtivas. Como consequência, ampliou-se a necessidade de socialização dos "códigos formais" básicos (leitura e escrita, por exemplo) necessários para integração de novos trabalhadores no novo processo produtivo. Um cenário em que a escola moderna se constituiu como forma predominante de socialização dos novos membros dessa sociedade (SAVIANI, 2013).

Inserida numa sociedade estruturalmente desigual, a escola moderna surge, e se mantém até os dias de hoje, como instrumento crucial e estratégico para a reprodução das condições sociais, apesar de, contraditoriamente e dialeticamente, abrir a possibilidade, ainda que limitada e parcial, para a transformação da realidade dada (SAVIANI, 2013). Um "risco" alertado na célebre e popular - que dispensa referência - afirmação de Adam Smith, na qual o autor reconhece a admite a necessidade de generalizar a instrução formal para a classe trabalhadora, desde que em doses homeopáticas e controladas.

Partimos, portanto, da ideia de que a educação formal "[...] ainda que elemento determinado, não deixa de influenciar o elemento determinante. Ainda que secundário, nem por isso deixa de ser instrumento importante e por vezes decisivo no processo de transformação da sociedade" (SAVIANI, 1999, p. 75).

Para uma postura crítica e transformadora ante essa realidade, entendemos que escola pública brasileira não pode se limitar a oportunizar o mínimo necessário para a inserção no mundo produtivo. A educação não deve perder de vista o compromisso político de possibilitar aos alunos o acesso aos conhecimentos produzidos no seio da sociedade, sem restrições, como forma de potencializar a sua atuação cidadã no mundo, na busca por uma vida digna para si e na colaboração coletiva de um processo de (re)construção de uma sociedade cada vez mais justa e igualitária (LIBÂNEO, 2012; SAVIANI, 2019).

Dito isso, ressaltamos que as estratégias pedagógicas de ensino-aprendizagem, o acompanhamento pedagógico e, especialmente importante para essa análise, a avaliação, estão inscritas na dimensão técnica necessária para a realização do compromisso político da escola. Como defende Saviani (2013): 
[...] a competência técnica é uma das (não a única) formas através das quais se realiza o compromisso político. Isto significa que ela permite (entre outras condições) efetuar a passagem entre o horizonte político (o compromisso político como uma possibilidade delineada no horizonte) e compromisso político assumido na nossa prática profissional cotidiana (SAVIANI, 2013, p. 31):

Nesse sentido, as práticas pedagógicas que se propõem contra hegemônicas precisam estar em permanente suspeição, investigação e crítica ante as formas de regulação do capitalismo, mais ou menos explícitas, sobre a escola moderna na contemporaneidade.

Considerando a avaliação do processo de ensino-aprendizagem como uma importante prática pedagógica escolar, objetivamos evidenciar as teorizações de avaliação que contribuem para o desvelamento desses processos de regulação, favorecendo uma perspectiva crítica e sistemática sobre a realidade escolar e, consequentemente, a potencialização de práticas pedagógicas alternativas.

Buscamos, dessa forma, escapar da perspectiva de avaliação do ensino-aprendizado como uma prática estritamente operacional/técnica, que se resume na elaboração, aplicação e correção dos instrumentos avaliativos (provas, trabalhos, exercícios etc.), mas como uma prática que, para além da competência técnica, deve estar conscientemente alinhada aos compromissos políticos da educação escolar que se propõe.

Para isso, realizamos uma pesquisa bibliográfica com o intuito de trazer para o debate os autores que contribuem para esse olhar acerca da avaliação do ensinoaprendizado.

Esse estudo faz parte de uma pesquisa de mestrado que busca compreender os sentidos de avaliação produzidos por professores da Educação Profissional Técnica Integrada ao Ensino Médio no âmbito do Instituto Federal do Espírito Santo - Ifes. A pesquisa, vinculada ao Programa de Mestrado Profissional em Educação Profissional e Tecnológica do Ifes, campus Vitória - ES, encontra-se em andamento.

\section{Fundamentação}

A busca bibliográfica teve como ponto de partida a organização da produção acadêmica na área de avaliação do ensino-aprendizado realizada por Fernandes (2009). O autor organiza as tendências de avaliação em quatro gerações, conforme tabela 1: 
Tabela 1 - Gerações de avaliação

\begin{tabular}{|l|c|}
\hline Gerações & $\begin{array}{c}\text { Período aproximado de produção e } \\
\text { predomínio acadêmico da ideia }\end{array}$ \\
\hline $1^{\text {a }}-$ A avaliação como medida & De 1900 a 1930 \\
\hline $2^{\underline{a}}-$ A avaliação como descrição & De 1930 a 1945 \\
\hline $3^{\underline{a}}-$ A avaliação como juízo de valor & De 1958 a 1972 \\
\hline $\begin{array}{l}4^{\text {a }}-\text { A avaliação como negociação e } \\
\text { construção }\end{array}$ & A partir de 1980 \\
\hline
\end{tabular}

Fonte: Fernandes (2009).

A terceira e a quarta gerações, notadamente importantes para o nosso estudo, discutem como as questões extraescolares influenciam o processo de avaliação na escola, ao contrário da primeira e segunda gerações, restritas às questões operacionais do processo.

Nas duas primeiras gerações, a saber, a avaliação assume, grosso modo, uma função de mensuração - pretensiosamente objetiva e neutra - do conhecimento aprendido pelo educando, cujo resultado ora servirá como instrumento de comparação do rendimento escolar do estudante (geração de avaliação como medida) com o dos seus pares, ora dentro de uma perspectiva produtivista, como instrumento de comparação entre o "nível dos estudantes" e os conhecimentos pré-definidos a partir dos objetivos escolares (geração de avaliação como descrição).

As teorizações da terceira geração, apesar de manterem o viés de mensuração - ou como Luckesi (2011) chama, a "qualificação" - das aprendizagens como procedimento objetivamente possível, não utiliza os seus resultados avaliativos para a competição ou classificação dos estudantes. Ao contrário, valem-se deles para diagnosticar quais as dificuldades e potencialidades dos educandos e dos professores, com vistas a melhoria do processo de ensino-aprendizado. Com intuito de uma análise global desse processo educativo, portanto, passou-se a considerar a influência do contexto econômico, social e familiar dos estudantes que ingressam na escola (FERNANDES, 2009).

Segundo esse autor, a ideia de avaliação formativa, nascida nessa geração, representa um importante salto teórico em direção à postura de investigação dos diferentes processos de aprendizagem e de ensino. Nessa concepção, a produção de diagnóstico não necessariamente coincide com a produção de testes, provas ou avaliações de quaisquer formas. Passa-se a assumir que os processos de avaliação não cabem na realização de avaliações formalizadas, já que demandam uma análise holística do sujeito. Uma proposta 
que esboça, ainda que de forma incipiente, uma análise da correlação entre a avaliação do ensino-aprendizado escolar e as formas regulatórias externas à escola.

Uma das principais críticas a essa geração é que apesar da postura diagnóstica, essa produção teórica ainda está ancorada na "racionalidade técnica", denunciada por Santos (2010). A proposta guarda uma herança positivista que se esforça por afastar a subjetividade do processo educativo e apresenta nos objetivos escolares um parâmetro homogeneizador e inquestionável (AFONSO, 2000). Isto é, apesar de a avaliação estar a serviço do processo de ensino-aprendizado, não se questiona quais são esses objetivos escolares que (i)mobilizam o processo educativo, e, porque, linear e homogeneamente, todo educando precisa obtê-los, sem os quais ficará reprovado. Não se questiona, em outras palavras, em que medida os conhecimentos científicos, artísticos e culturais, representados na escola pelos conhecimentos escolares/curriculares, importantes para a aprendizagem ampla dos educandos, são utilizados para homogeneizar os sujeitos a partir de um parâmetro único e imutável, e não para potencializá-los individual e coletivamente.

A geração da avaliação como negociação e construção (quarta geração), busca romper com a racionalidade técnica presente nas três gerações anteriores. Defende que devemos negociar e definir os objetivos escolares a partir de processos dialógicos que considerem a complexidade do processo educativo e o contexto dos sujeitos da escola, no lugar de concedê-los o status de imperiosidade sobre a educação (FERNANDES, 2009). Na tentativa de homogeneizar um processo educativo protagonizado por sujeitos tão diversos, nos submetemos ao risco de negar, silenciar e excluir os sujeitos e suas formas diversas de ser e estar no mundo (ESTEBAN, 2008).

É uma geração que, para além de ter a avaliação a serviço da investigação da aprendizagem e do ensino, como já apontava a geração anterior, busca ampliar o diálogo entre os saberes escolares - científicos, artísticos e culturais legitimados - e os trazidos pelos estudantes - senso comum -, bem como as suas diversidades culturais, as diferentes perspectivas que esses sujeitos trazem para a escola e as suas subjetividades.

\section{Metodologia}

Para atingir os objetivos traçados, optamos por uma perspectiva qualitativa de investigação, de cunho exploratório, a partir do uso de pesquisa bibliográfica. A técnica de pesquisa bibliográfica colaborou para reunirmos um rico conjunto de teorizações acerca da avaliação do processo de ensino-aprendizado, a partir do estudo de livros dos principais autores da área, obras são consideradas "fontes bibliográficas por excelência", conforme Gil (2002, p. 44). 
Optamos pela abordagem qualitativa uma vez que essa permite o diálogo com os significados produzidos pelo coletivo de autores nas suas experiências teórico-práticas (MINAYO, 2009), e pelo objetivo exploratório, já que pretendemos compreender melhor o tema a fim de aprimorar as ideias acerca dele (GIL, 2002).

A escolha pelas linhas teóricas privilegiou aqueles autores inseridos na geração de "avaliação como juízo de valor" (terceira geração) e na geração de "avaliação como negociação e construção" (quarta geração), conforme organização proposta por Fernandes (2009). Essas gerações, notadamente a quarta, foram escolhidas porque discutem a avaliação para além da sua operacionalização técnica, revelando as conexões entre essa temática e as questões sociais mais amplas.

Buscamos, portanto, traçar aproximações entre as produções de Afonso (2000), Esteban (2001; 2008; 2010), Luckesi (2011), Lugli e Gualtieri (2012) e Vasconcellos (2000), colocando em evidência e em diálogo as ideias que contribuem para os objetivos desse trabalho.

\section{Resultados e Discussão}

Guardadas as especificidades e contradições, a partir da contribuição realizada pelos autores representantes da terceira e da quarta gerações de avaliação, entendemos e defendemos aqui que as diferentes formas de regulação exercidas pelo sistema capitalista podem ocorrer de forma imediata e/ou mediata.

A forma imediata (sem mediação), ocorre quando o próprio processo avaliativo, diretamente e sem mediações, tem a função de socialização dos sujeitos escolares, seja quando é utilizado como forma de poder, de coação ou disciplinamento. Nesse caso, a avaliação influencia de forma imediata na socialização dos sujeitos, sem o intermédio dos outros processos escolares. As regras estruturantes do processo avaliativo, por si só, buscam a reprodução de comportamentos úteis para a aceitação passiva das regras de funcionamento da sociedade capitalista e da forma do trabalho humano nessa sociedade.

Por outro lado, a forma mediata (com mediação) se dá quando a avaliação, inscrita no campo da didática, está deliberadamente a serviço da seleção e da promoção dos "mais inteligentes" em detrimento dos "menos inteligentes". É uma forma de regulação mediata, pois se dá por meio da mediação do processo de ensino-aprendizagem. Nesse caso, a avaliação, por meio do processo educativo, contribui para reprodução das desigualdades cognitivas, e, consequentemente, sociais e econômicas, na forma do fracasso e da evasão escolares.

Apesar dessa possibilidade conceitualização e de organização, não acreditamos que essas duas formas de regulação ocorrem de forma mecânica e estanque na realidade da 
escola. Pelo contrário, reconhecemos que esse processo se dá de forma complexa e dinâmica, sem os limites teóricos aqui apresentados.

Como forma imediata de socialização dos indivíduos, Afonso (2000) afirma que:

"[...] a escola, é, assim, a agência de socialização na qual as crianças experimentam pela primeira vez um sistema institucionalizado de diferenciação com base na realização individual, o qual procura incutir a aceitação das regras de competição próprias da estrutura social e econômica" (AFONSO, 2000, p. 24).

Nesse contexto, o autor aponta que os processos avaliativos, via de regra, contribuem fundamentalmente para a interiorização de normas sociais necessárias para a vida e para o trabalho no sistema capitalista. Relaciona a "compulsão" dos professores em avaliar individualmente, de saber o que cada um aprendeu e de saber com profundidade o potencial dos seus alunos com uma forma implícita de se comunicar com o mercado de trabalho, que também apresenta tal "compulsoriedade", já que almeja trabalhadores capazes de "assumir as suas próprias responsabilidades" e de dar conta de suas tarefas diárias individualmente. De forma geral, a avaliação pode, nesse sentido, contribuir para "[...] preparar o sujeito para a ordem, o ritmo, o controle, a hierarquia, o trabalho para o outro [...]" (VASCONCELLOS, 2000, p. 28).

Além dessa análise, Afonso (2000) pondera o aspecto alienante das atividades avaliativas. Para ele, a forma como elas são realizadas nas escolas são uma preparação para o mercado de trabalho. Os alunos aprendem a executar tarefas das quais não participaram do planejamento e da execução, e a cumprir critérios alheios às suas vontades para produção de um resultado (notas boas) com vistas a satisfazer, não a si mesmos, mas a terceiros (pais ou professores). Um modus operandi equivalente ao do trabalhador que aliena sua força de trabalho em troca de um salário. Nesse modelo, "A alienação resulta da percepção de que o trabalho escolar não é para ser apropriado por quem o realiza, mas para ser entregue a um avaliador" (AFONSO, 2000, p. 25). A aprendizagem deixa de servir à satisfação do sujeito que aprendeu e passa a servir a interesses alheios.

Uma outra faceta da via imediata ocorre por meio da aplicação, na escola, da ideia de "igualdade formal" - fundamento jurídico da sociedade capitalista, por meio do qual "todos são iguais perante a lei". Nesse sentido, concordamos com Esteban (2001, p. 103104) quando assinala que "[...] o sistema de avaliação é uma parcela do sistema educativo organizado por uma sociedade que tem como um de seus pilares a igualdade formal".

A concepção de igualdade formal traz uma percepção de que a mera oportunidade de estar na escola já faz cumprir o dever social da escola para com o educando, restando este reunir esforços para aprender e para se formar. Trata-se de um processo pautado na "meritocracia" que estimula a competição entre os estudantes, exemplificado pelo momento 
caricato da entrega das provas corrigidas, no qual enquanto alguns se vangloriam pelos resultados positivos, disputando a "melhor nota da sala", outros se envergonham e escondem suas notas. Quando utilizado de forma sistemática, esse modelo contribui para que os estudantes interiorizem a responsabilidade pelo seu sucesso ou fracasso na escola, e, fora dela, na disputa de um emprego. Na escola, isso alivia a responsabilidade dos sistemas de ensino, dos gestores e dos professores sobre o destino dos estudantes e, na vida adulta, reduz a responsabilidade dos governos pela garantia do direito constitucional ao trabalho (BRASIL, 1988).

No âmbito das relações de poder, Luckesi (2011) aponta que os processos avaliativos baseados na aplicação de exames - fundados na alienação do processo de aprendizagem, como já vimos - transforma a nota/conceito numa "moeda de troca" entre professor e educando e, com isso, produz uma relação desigual de poder. Por medo de uma nota baixa, o educando "vira a noite", perde feriados e fins de semana estudando e, esse cenário, se não questionado, pode levar ao professor a construção da lógica de que "quanto mais difícil e temerosa a avaliação, mais os estudantes vão se dedicar". Uma ideia apresentada na obra Didática Magna de Comenius, publicada em 1946, quando questionava: "Que estudante não se preparará suficientemente bem para as provas se souber que elas são para valer?" (COMENIUS, 1946 apud LUCKESI, 2011, p. 249).

Daí emerge a relação de poder, a partir do medo. Como a nota é determinante para que o estudante "passe de ano", para que ele não fique de castigo em casa e para que consiga se destacar entre os amigos, o professor, desatento em relação ao compromisso político da educação escolar, pode utilizar-se disso para disciplinar o comportamento da turma, conseguir silêncio com as ameaças, por exemplo, de que o conteúdo "vai cair na prova". O autor acrescenta que, à imagem dos castigos corporais, hoje proibidos, as pressões derivadas desses processos de avaliação também produzem consequências físicas nos estudantes, como "dificuldade de respirar", "suor nas mãos", "crise de choro", além de problemas psicológicos (LUCKESI, 2011).

Nesse sentido, Esteban (2001) contribui com a discussão ao aproximar teoricamente as relações de poder - especialmente no escopo do disciplinamento -, com o carácter individualizador e classificatório dos exames escolares. Por meio de movimento de homogeneização das características individuais, via estabelecimento de padrões únicos de aprendizagem, é possível comparar os rendimentos dos alunos a ponto de hierarquizá-los e expô-los via um rígido processo de "sistema de registro". Tal conformação dá "validade" aos resultados obtidos, permitindo uma vigilância e um disciplinamento eficaz. A autora aponta ainda que tal postura coloca a escola como prestadora de um serviço de informações acerca dos alunos, fundamentalmente importante para um sistema produtivo que tem o conhecimento como "moeda de troca", inclusive para o cálculo do valor da força de trabalho. 
A respeito desse tema, a autora destaca que o disciplinamento do sujeito pode ocorrer por meio da "violência simbólica" que, segundo ela é "[...] menos perceptível, dificulta que o sujeito identifique o agressor, o que contribui para que ele vá internalizando um forte sentimento de inferioridade e de culpa pelo seu fracasso [...]" (ESTEBAN, 2001, p. 108).

Na perspectiva da relação mediata (com mediações), a ideia de igualdade formal na escola também produz efeitos nos processos sociais mais amplos. Ao promover um movimento de disputa e competição entre os educandos, os processos avaliativos pautados nos exames legitimam a desigualdade no desempenho escolar dos sujeitos, sem, contudo, colocar em discussão nesse processo o papel da escola numa sociedade estruturalmente desigual (VASCONCELLOS, 2000).

Nessa ótica, "[...] a diferença de resultados se entende como a confirmação de que pessoas diferentes devem ocupar lugares diferentes, o que em nossa sociedade significa possuir direitos e qualidade de vida diferentes", assinala Esteban (2001, p. 24).

Tendemos a concordar que os exames escolares são um formato de avaliação cujas finalidades se conectam com as questões de desigualdade social persistentes para além dos muros da escola. Nessa análise, a relação entre a prática dos exames numa sociedade marcada pela desigualdade social, baseada na competitividade, na meritocracia e na igualdade formal com "o respaldo legal para a reprovação", agravam potencialmente as desigualdades já existentes (VASCONCELLOS, 2000).

Os estudos sobre o fracasso escolar dialogam com essa perspectiva ao defender que nos diferentes momentos históricos, em que pese as diferentes formas de tratar o tema, hegemonicamente, as explicações das suas causas colocavam para o estudante os louros do sucesso ou o fardo do fracasso, ofuscando a parcela de responsabilidade da escola nesse processo de produção coletiva do conhecimento (LUGLI; GULATIERI, 2012).

Ao assumir uma percepção complexa do fracasso escolar, incluindo a possibilidade do "fracasso da escola", as autoras apontam que a partir da criação unilateral de ritmos, e a conformação de processos, procedimentos e formatos estandardizados dos temposespaços de produção de conhecimento e de realização de si mesmos, incompatíveis muitas vezes com a diversidade do seu público, a escola contribui com o distanciamento de alguns sujeitos. Lugli e Gualtieri (2012) concluem que:

"[...] tem sido subestimada a hipótese de que o comportamento indesejado da criança e do jovem, com apatia, agitação, agressividade, que, geralmente, acompanha o insucesso escolar, possa decorrer precisamente daquilo que ela experimenta na escola" (LUGLI e GUALTIERI, 2012, p. 108) 
Incluímos nessa estrutura homogeneizadora as questões relativas à avaliação escolar e à qualidade do ensino, por meio da análise de Esteban (2008). A autora afirma que o conceito de "qualidade", corporificado no conhecimento escolar e nos objetivos padronizados do ensino a serem "perseguidos" pelos educandos, contribuem - num contexto de diversidade de culturas, de experiências e de conhecimentos dos sujeitos escolares - para um projeto de homogeneização que nega as diversas formas e ritmos de aprendizagem e de produção de conhecimento, legitimando o não pertencimento das classes populares às escolas públicas. Um resultado perverso, uma vez que "[...] o fracasso pode significar o desejo de escola pelas classes populares, pois, para fracassar na escola é preciso estar nela, e simultaneamente sua recusa desse projeto de escola" (ESTEBAN, 2010, p. 49).

A qualidade do ensino aqui é mensurada a partir da avaliação escolar como instrumento capaz de identificar os "vencedores"/aprovados, de forma neutra, individualizada e descontextualizada da função social da escola, colocando de forma deliberada e perversa a discussão apenas no nível técnico-operacional, desconectado do compromisso político da educação. Essa perspectiva ofusca a função da educação como elemento da humanização e potencialização coletiva dos homens e do lugar central que a escola ocupa nesse processo.

\section{Considerações finais}

Compreendemos que o processo de regulação capitalista se dá de forma imediata e/ou mediata no âmbito das práticas de avaliação do processo de ensino-aprendizado. E que, em decorrência disso, importa a uma proposta de educação crítica e cidadã a reflexão acerca desses processos que impingem - hegemonicamente, mas não absolutamente - a escola a servir ao processo de reprodução das desigualdades sociais. Nesse sentido, revisitar, ressignificar e reinventar as práticas cristalizadas requer que olhemos para elas não apenas do espectro da capacitação técnica, objetivando aprender como organizar as questões de uma "prova" para que fique adequada aos propósitos da disciplina, ou técnicas para distribuição de pontuação no período letivo para contemplar uma gama maior de virtualidades dos estudantes. Também é crucial respondermos a seguinte questão: essa prática avaliativa está alinhada, imediata ou mediatamente, aos propósitos de uma educação escolar transformadora, inclusiva, potencializadora e cidadã, ou está alinhada aos propósitos de uma educação alienadora, excludente e subalternizadora? 


\section{Referências}

AFONSO, Almerindo Janela. Avaliação educacional: regulação e emancipação para uma sociologia das políticas avaliativas contemporâneas. São Paulo: Cortez, 2000.

BRASIL. Constituição da República Federativa do Brasil. Brasília: Presidência da República, 1988.

Disponível em: <https://www.planalto.gov.br/ccivil_03/Constituicao/Constituicao.htm>. Acesso em: 17 nov. 2020.

ESTEBAN, Maria Teresa. O que sabe quem erra? reflexões sobre avaliação e fracasso escolar. Rio de Janeiro: DP\&A, 2001.

Silenciar a polissemia e invisibilizar os sujeitos: indagações ao discurso sobre a qualidade da educação. Revista Portuguesa de Educação, v. 21, n. 1, p. 531, 2008. Disponível em: <https://doi.org/10.21814/rpe.13917>. Acesso em: 17 nov. 2020.

Diferença, aprendizagens e avaliação: perspectiva pós-colonial e escolarização. In: ESTEBAN, Maria Teresa (Org.); AFONSO, Almerindo Janela (Org.). Olhares e interfaces: reflexões críticas sobre a avaliação. São Paulo: Cortez, 2010.

FERNANDES, Domingos. Avaliar para aprender: fundamentos, práticas e políticas. São Paulo: Unesp, 2009.

GIL, Antônio Carlos. Como elaborar projetos de pesquisa. São Paulo: Atlas, 2002.

LEONTIEV, Alexei. O desenvolvimento do psiquismo. Lisboa: Livros Horizonte, 1978.

LIBÂNEO, José Carlos. 0 dualismo perverso da escola pública brasileira: escola do conhecimento para os ricos, escola do acolhimento social para os pobres. Educação e Pesquisa, v. 38, n. 1, p. 13-28, 2012.

LUCKESI, Cipriano Carlos. Avaliação da aprendizagem componente do ato pedagógico. São Paulo: Cortez, 2011.

LUGLI, Rosário Genta; GUALTIERI, Regina C. Ellero. A escola e o fracasso escolar. São Paulo: Cortez, 2012.

MARX, Karl; ENGELS, Friedrich. A Ideologia Alemã. São Paulo: Martins Fontes, 1998.

MINAYO, Maria Cecília de Souza (org). Pesquisa social: teoria, método e criatividade. Petrópolis: Vozes, 2009.

SANTOS, Boaventura de Sousa. Um discurso sobre as ciências. São Paulo: Cortez, 2010.

SAVIANI, Dermeval. Escola e Democracia. Campinas: Autores Associados, 1999. 
Trabalho e educação: fundamentos ontológicos e históricos. Revista Brasileira de Educação, v. 12, n. 34, p. 152-180, 2007. Disponível em: <https://doi.org/10.1590/S1413-24782007000100012>. Acesso em: 17 nov. 2020.

Pedagogia histórico-crítica: primeiras aproximações. Campinas:

Autores Associados, 2013.

Pedagogia histórico-crítica, quadragésimo ano: novas aproximações. Campinas: Autores Associados, 2019.

VASCONCELLOS, Celso dos Santos. Avaliação: concepção dialético-libertadora do processo de avaliação escolar. São Paulo: Libertad, 2000. 